\title{
FAKTOR RISIKO MORBIDITAS MATERNAL: DILIHAT ASPEK KUALITAS GENDER
}

\author{
Risk Factor Maternal Morbidty: Gender Quality Aspect
}

\author{
Agustin Dwi Syalfina ${ }^{1}$, Nurun Ayati Khasanah ${ }^{2}$, Wiwit Sulistyawati ${ }^{3}$ \\ ${ }^{123}$ Stikes Majapahit \\ agustinpipin2@gmail.com
}

\begin{abstract}
ABSTRAK
Kematian ibu merupakan fenomena gunung es yang disebabkan morbiditas maternal. Morbiditas maternal selama kehamilan paling tinggi terjadi di negara berkembang. faktor ekonomi, sosial dan budaya berperan penting terhadap komplikasi kehamilan sampai dengan kematian ibu. Ketidaksetaraan gender dimana banyaknya peran yang harus dilakukan oleh perempuan dibandingkan laki-laki dianggap sebagai kewajiban bahkan kodrat wanita serta sering tidak memiliki perlindungan ditempat kerja bahkan peran produktif perempuan kurang dihargai dibandingkan peran produktif laki-laki, hal tersebut menyebabkan tingginya kejadian komplikasi ketika hamil, bersalin dan nifas. Penelitian bertujuan untuk menganalisis pengaruh kualitas terhadap morbiditas maternal. Design penelitian menggunakan case control dengan jumlah sampel kasus 60 dan sampel kontrol 60. Data yang digunakan data primer diperoleh melalui kunjungan rumah dan teknik wawancara. Setelah itu data dianalis dengan uji regresi logistik. Hasil penelitian diperoleh kualitas gender dalam kategori kurang baik 17,864 kali berisiko menyebabkan morbiditas maternal $(\mathrm{OR}=17,864 ; 95 \% \mathrm{CI}=6,021-53,001 ; P$ value $=0,000)$. Morbiditas maternal berhubungan dengan beban kerja perempuan yang cukup berat dalam mengurus rumah tangga dan juga harus mencari nafkah untuk menutupi kekurangan pendapatan rumah tangga sehingga waktu kerja lebih panjang perharinya. Beban kerja yang berat tanpa adanya upaya suami untuk membantu mengurangi beban kerja ibu secara tidak langsung mendorong kerentanan tubuh ibu saat hamil. Kesetaraan gender sebagai upaya memperbaiki kualitas gender berpengaruh menurunkan kejadian morbiditas maternal. Petugas kesehatan di harapkan mensosialisasikan tentang kualitas gender selamaa kehamilan dan meningkatan peran serta suami dalam kesehatan ibu selam kehamilan sampai dengan nifas.
\end{abstract}

Kata Kunci : Kualitas, Gender, Morbiditas, Maternal

\begin{abstract}
Maternal mortality was an iceberg phenomenon caused by maternal morbidity. Maternal morbidity during pregnancy was highest in developing countries. Economic, social and cultural factors play an important role in complications of pregnancy until the death of the mother. Gender inequality in which the many roles that women have to play with men was considered an obligation of even the nature of women and often lacks protection at work even the productive role of women was less valued than the productive role of men, which causes a high incidence of complications during pregnancy, maternity and childbirth. The study aimed to analyze the effect of quality on maternal morbidity. The research design used case control with 60 cases and 60 control samples. The data used were primary data obtained through home visits and interview techniques. After that the data is analyzed by logistic regression test. The results showed that gender quality in the poor category was 17,864 times at risk of causing maternal morbidity $(O R=17,864 ; 95 \% C I=6,021-53,001 ;$ Pvalue $=0,000)$. Maternal morbidity was related to women's heavy workload in managing the household and also have to make a living to cover the shortage of household income so that the working time is longer per day. The heavy workload without the husband's efforts to help reduce the workload of the mother indirectly encourages the vulnerability of the mother's body during pregnancy. Gender equality as an effort to improve gender quality has an effect on reducing the incidence of maternal morbidity. Health workers are expected to socialize about gender quality during pregnancy and increase the role of husbands in maternal health during pregnancy to postpartum.
\end{abstract}

Keywords : Quality, Gender, Morbidity, Maternal 


\section{PENDAHULUAN}

Morbiditas merupakan kata dari bahasa latin "morbidus" yang mengandung arti menunjukkan gejala sakit atau sedang mengalami masalah kesehatan yang membutuhkan perawatan medis. Maternal sebutan untuk ibu. Morbiditas maternal adalah kesakitan atau masalah yang berhubungan dengan kondisi kesehatan ibu pada masa kehamilan, persalinan sampai dengan nifas. Morbiditas maternal menyebabkan fenomena gunung es setiap tahun di setiap Negara, karena 700 wanita meninggal per tahun dikarenakan komplikasi selama kehamilan dan 75 sampai dengan $100 \mathrm{ibu}$ dengan komplikasi berat (Callaghan, 2018). Angka kematian ibu di beberapa bagian dunia mencerminkan ketidakadilan dalam akses ke layanan kehamilan dikarenakan adanya kesenjangan dalam mendapatkan pelayanan kesehatan antara kaya dan miskin. Menurut Tabassum Firoz el, 2013 "Maternal morbidity can be conceptualized as a spectrum ranging, at its most severe, from a "maternal near miss" defined by the World Health Organization (WHO) as the near death of a woman who has survived a complication occurring during pregnancy or childbirth or within 42 days of the termination of pregnancy - to non-lifethreatening morbidity, which is more common by far". Hampir $100 \%$ kematian ibu secara global terjadi di negara berkembang (WHO, 2019).

Menurut Aeni, 2013 faktor risiko penyebab tingginya kematian ibu dalah morbiditas maternal yang dengan besar risiko 12,198. Komplikasi kehamilan yang mempengaruhi kematian ibu meliputi penyakit jantung, pre eklampsia/eklampsia, perdarahan. Peningkatan angka kematian ibu juga terjadi di kabupaten Mojokerto mulai tahun 2014 sampai dengan tahun 2017 yaitu sebesar 90,7 per $100.00 \mathrm{KH}$ menjadi 174 per $100.000 \mathrm{KH}$ disebabkan morbiditas maternal yaitu perdarahan, preeklamsia dan penyakit penyerta (penyebab lain).

Preeklampsia/eklampsia adalah salah satu dari 3 penyebab utama morbiditas dan mortalitas ibu di seluruh dunia. Kematian ibu, dan morbiditas ibu di negara maju karena eklampsia terjadi penurunan yang signifikan dalam kurun waktu 50 tahun terakhir, Sebaliknya komplikasi dan kematian ibu dengan eklampsia masih tinggi di negara berkembang. Sebagian besar kematian dan komplikasi ibu karena Preeklampsia atau eklampsia disebabkan rendahnya kualitas prenatal care, ketidaterjangkauan akses ke pelayanan rumah sakit, kurangnya sumber daya, serta diagnosis dan manajemen yang tidak tepat pasien dengan preeklampsiaeklampsia di negara berkembang (Ghulmiyyah dan Sibai, 2012).

Menurut penelitian NM Ibraheem, 2016 bahwa komplikasi kehamilan yaitu pre eklamsia, $61,5 \%$ terjadi pada ibu dengan beban pekerjaan ganda yaitu sebagai ibu rumah tangga dan pekerja. Hal ini karena beban pekerjaan yang berat di tempat pekerjaannya selain pekerjaan menjadi ibu rumah tangga dan tekanan psikologis yang tinggi dapat meningkatkan kadar katekolamin. Peningkatan kadar katekolamin menurunkan aliran darah ke uterus sehingga memicu terjadinya preeklamsia. Beban kerja yang berat tanpa dibantu suami untuk mengurangi beban kerja ibu secara tidak langsung mendorong penurunan kondisi tubuh ibu saat hamil secara fisiologis (Budi Rajab, 2009). Pembagian Beban kerja ibu hamil menggambarkan kualitas gender pada keluarga tersebut. Tujuan penelitian adalah menganalisis pengaruh kualitas gender terhadap morbiditas maternal di Kabupaten Mojokerto.

\section{METODE}

Desain Penelitian adalah penelitian observasional pendekatan case control. Penelitian dimulai dengan identifikasi ibu hamil TM III dengan morbiditas maternal (kelompok kasus) dan ibu hamil III dengan kehamilan normal (kelompok kontrol), kemudian dilakukan penelusuran kebelakang (retrospektif) untuk mengidentifikasi kualitas gender untuk dilihat besar faktor risiko kualitas gender terhadap Mobirditas Maternal dengan membandingkan kelompok kasus dan kelompok kontrol berdasarkan paparan.

Populasi penelitian meliputi populasi kasus dan populasi kontrol. Populasi kasus adalah semua ibu trimester III yang mengalami morbiditas maternal di Kabupaten Mojokerto 
Tahun 2019. Populasi kontrol adalah semua ibu hamil trimester III dengan kehamilan normal di Kabupaten Mojokerto Tahun 2019. Data populasi kasus dan control diperoleh Rumah Sakit. Sampel kasus dan Kontrol diambil secara simple random sampling diperoleh sampel minimal dengan $\mathrm{P}_{2}$ dan $\mathrm{OR}$ yang digunakan dari penelitian Nelyta (2014) yaitu 52, Untuk mengantisipasi kehilangan data, ditambahkan $10 \%$, maka sampel didapat sebanyak 60 orang. perbandingan kelompok kasus dan kontrol 1:1, sehingga total sampel adalah 120 orang. Variabel penelitian yaitu variabel dependent adalah morbiditas maternal sedangkan Variabel independent adalah kualitas gender. Data diperoleh dengan melihat rekam medis pada poli kandungan RSUD Prof. DR Soekandar dan wawancara dengan melakukan kunjungan rumah. Data yang diperoleh diolah dan dianalisis dengan menggunakan uji regresi logistic.

\section{HASIL DAN PEMBAHASAN HASIL}

Umur responden berdasarkan tabel 1 bahwa hampir seluruhnya memiliki umur tidak berisiko (20-35 tahun) sebesar 99 responden $(82,5 \%)$ dan 21 responden $(17,5 \%)$ termasuk kelompok umur berisiko (>35 tahun). Responden dengan umur berisiko 54(54,5\%) tidak mengalami morbiditas maternal dibandingkan yang tidak berisiko, sedangkan responden berumur tidak berisiko $15(71,4 \%)$ dengan morbiditas maternal. Morbiditas maternal hampir seluruhnya (90\%) tidak dialami pada kelompok berumur 20-35 tahun akan tetapi sebagian besar (75\%) kejadian morbiditas maternal terjadi pada responden dengan umur 20-35 tahun.

Tabel 1 Distribusi Frekuensi Variabel Karakteristik, Keteraturan dan Jumlah kunjungan Antenatal Care (ANC), Kualitas Gender Di Kabupaten Mojokerto Tahun 2019

\begin{tabular}{lcc}
\hline \multicolumn{1}{c}{ Variabel } & F & \% \\
\hline Umur Ibu & & \\
Berisiko & 21 & 17,5 \\
Tidak berisiko & 99 & 82,5 \\
\hline Pendidikan Ibu & & \\
SD-SMP & 41 & 34,2 \\
\hline
\end{tabular}

\begin{tabular}{lcc}
\hline SMU-PT & 79 & 65,8 \\
\hline Sosial ekonomi keluarga & & \\
Kurang (<UMR) & 75 & 62,5 \\
Cukup ( $\geq$ UMR) & 45 & 37,5 \\
\hline Paritas & & \\
Primigravida - grande multi & 34 & 28,3 \\
Multigravida & 86 & 71,7 \\
\hline Keteraturan ANC & & \\
Tidak teratur & 31 & 25,8 \\
$\quad$ Teratur & 89 & 74,2 \\
\hline Jumlah kunjungan ANC & & \\
$<8$ & 52 & 43,3 \\
$\geq 8$ & 68 & 56,7 \\
\hline Kualitas Gender & & \\
Kurang baik & 73 & 60,8 \\
Baik & 47 & 39,2 \\
\hline
\end{tabular}

Sumber: Data Primer

Pendidikan ibu ditemukan pada penelitian ini bahwa sebagian besar $(65,8 \%)$ memiliki pendidikan SMU-PT dan sebagian kecil $(34,2 \%)$ berpendidikan SD-SMP, tidak ada satupun ibu yang tidak sekolah. Kejadian morbiditas maternal pada ibu dengan pendidikan SD-SMP dan SMU-PT berproporsi sama sebesar 26(43,3\%) dan 34(56,7\%), namun kehamilan normal sebagian besar dialami oleh ibu dengan pendidikan SMU-PT 45(75\%). Dari aspek sosial ekonomi pada penelitian ini dilihat dari jumlah pendapatan keluarga tiap bulan disesuaikan upah minimum pada kabupaten Mojokerto. Sebagian besar responden memiliki keadaan sosial ekonomi dalam kategori kurang sebesar 75 (62,5\%) dan sebagian kecil dengan keadaan sosial ekonomi cukup 45(37,5\%). Responden dengan sosial ekonomi kurang sebagian besar mengalami kejadian morbiditas maternal yaitu $44(58,7 \%)$ dan morbiditas maternal sebagian besar tidak dialami oleh responden dengan sosial ekonomi keluarga cukup sebesar 29(64,4\%). Morbiditas maternal 44(73,3\%) terjadi pada ibu dengan keluarga berpendapatan kurang dari UMR.

Berdasarkan paritas, ditemukan sebagian besar $86(71,7 \%)$ ibu berparitas tidak berisiko yaitu dalam kategori multigravida dan $34(28,3 \%)$ termasuk paritas berisiko (primigravida dan grande multigravida). Paritas berisiko memiliki perbandingan presentasi yang sama antara kejadian morbiditas maternal dan tidak mengalami morbiditas maternal sebesar $16(47,1 \%)$ dan $18(52,9 \%)$. Hal ini terjadi juga pada presentase kejadian 
morbiditas maternal dan tidak morbiditas maternal pada kelompok paritas primigravida/grande multigravida yaitu $44(51,2 \%)$ dan $42(48,8 \%)$.

Antenatal care responden selama kehamilan dilihat dari keteraturan kunjungan tiap trimester dan jumlah kunjungan untuk datang memeriksakan kehamilan. Keteraturan antenatal care responden sebagian besar $89(74,2 \%)$ termasuk teratur dalam melakukan pemeriksaan kehamilan tiap trimester dan $31(25,8 \%)$ responden tidak teratur dalam melakukan kunjungan antenatal care. Responden yang tidak teratur berkunjung untuk pemeriksaan kehamilan $19(61,3 \%)$ dengan morbiditas maternal dan $12(38,7 \%)$ tidak dengan morbiditas maternal. Responden dengan antenatal care teratur menunjukkan bahwa 41(46,1\%) terjadi morbiditas maternal. Berdasarkan jumlah kunjungan antenatal care sebagian besar 68(56,7\%) ibu melakukan kunjungan pemeriksaan kehamilan ke petugas kesehatan $\geq 8$ kali dan sebagian kecil 52(43,3) $<8$ kali. Ibu dengan kunjungan kehamilan lebih dari sama dengan 8 kali $60,3 \%$ tidak mengalami kejadian morbiditas maternal sedangkan ibu yang kurang dari 8 pemeriksaan kehamilan $63,5 \%$ dengan morbiditas maternal.

Tabel 2 Analisis Bivariat Faktor Risiko Morbiditas Maternal Di Kabupaten Mojokerto Tahun 2019

\begin{tabular}{lccc}
\hline \multicolumn{1}{c}{ Variabel } & OR & $\mathbf{9 5 \%}$ CI & Pvalue \\
\hline $\begin{array}{l}\text { Umur Ibu } \\
\text { Berisiko } \\
\text { Tidak } \\
\text { berisiko }\end{array}$ & 3,000 & $1,075-8,370$ & 0,036 \\
\hline $\begin{array}{l}\text { Pendidikan } \\
\text { Ibu }\end{array}$ & & & \\
$\begin{array}{l}\text { SD-SMP } \\
\text { SMU-PT }\end{array}$ & 2,294 & $1,056-4,985$ & 0,036 \\
\hline $\begin{array}{l}\text { Sosial } \\
\text { ekonomi } \\
\text { keluarga }\end{array}$ & & & \\
$\begin{array}{l}\text { Kurang } \\
\text { (<UMR) }\end{array}$ & 2,573 & $1,198-5,523$ & 0,015 \\
$\begin{array}{l}\text { Cukup } \\
\text { ( } \geq \text { UMR) }\end{array}$ & & & \\
\hline $\begin{array}{l}\text { Paritas } \\
\text { Primigravida } \\
\text { - grande } \\
\text { multi }\end{array}$ & 1,179 & $0,532-2,610$ & 0,685 \\
Multigravida & & & \\
\hline
\end{tabular}

\begin{tabular}{lccc}
\hline Keteraturan & & & \\
ANC & & & \\
Tidak teratur & 1,854 & $0,805-4,269$ & 0,144 \\
Teratur & & & \\
\hline $\begin{array}{l}\text { Jumlah } \\
\text { kunjungan }\end{array}$ & & & \\
$\begin{array}{l}\text { ANC } \\
<8\end{array}$ & 2,637 & $1,252-5,554$ & 0,010 \\
$\geq 8$ & & & \\
\hline $\begin{array}{l}\text { Kualitas } \\
\text { Gender }\end{array}$ & & & \\
$\begin{array}{l}\text { Kurang baik } \\
\text { Baik }\end{array}$ & 9,788 & $4,052-23,644$ & 0,000 \\
\hline Sumber: Data Primer & & \\
\hline
\end{tabular}

Sumber: Data Primer

Kualitas gender responden sebagian besar 73(60,8\%) dalam kategori kurang baik dan 47(39,2\%) dengan kualitas gender kategori baik. Responden dengan kualitas gender kurang baik, 51(69,9\%) mengalami kejadian morbiditas maternal namun responden yang memiliki kualitas gender dengan kriteria baik $38(80,9 \%)$ tidak mengalami kejadian morbiditas maternal. Hasil analisis bivariat antara karakteristik dan kualitas gender terhadap kejadian morbiditas maternal menunjukkan pengaruh signifikan pada variabel umur ibu $(\mathrm{OR}=3,000 ; 95 \%$ $\mathrm{CI}=1,075-8,370 ; \quad P$ value $=0,036), \quad$ pendidikan ibu $(\mathrm{OR}=2,294 ; 95 \% \quad \mathrm{CI}=1,056-4,985$; $P$ value $=0,036)$, sosial ekonomi $(\mathrm{OR}=2,573$; 95\% CI=1,198-5,523; Pvalue=0,015), jumlah kunjuangan antenatal care $(\mathrm{OR}=2,637 ; 95 \%$ $\mathrm{CI}=1,252-5,554 ; \quad P$ value $=0,010), \quad$ kualitas gender $(\mathrm{OR}=9,788 ; 95 \% \mathrm{CI}=4,052-23,644$; $P$ value $=0,000)$ terhadap morbiditas maternal. Uji multivariate antara semua variabel dengan mempertimbangkan variabel confounding diperoleh 4 variabel yang paling berpengaruh terhadap kejadian morbiditas maternal yaitu umur $(\mathrm{OR}=4,806 ; 95 \% \mathrm{CI}=1,241-18,620$; $P$ value $=0,023)$, sosial ekonomi $(\mathrm{OR}=4,756$; 95\% CI=1,725-13,110; $P$ value $=0,003)$, jumlah kunjungan antenatal care $(\mathrm{OR}=2,908 ; 95 \%$ CI $=1,139-7,425 ; \quad P$ value $=0,026)$ dan kualitas gender $(\mathrm{OR}=17,864 ; 95 \% \mathrm{CI}=6,021-53,001$; $P$ value $=0,000)$. Nilai nagelkerke $R$ square yang diperoleh sebesar 0,486 artinya 48,6\% kejadian morbiditas maternal diprediksi dari variabel umur ibu, sosial ekonomi, jumlah kunjungan antenatal care dan kualitas gender 


\section{PEMBAHASAN}

Morbiditas maternal yang dialami oleh reponden pada penelitian ini diantaranya pre eklamsi, anemia, dan hepatitis. Faktor risiko yang yang berpengaruh salah satunya faktor umur ibu. Kelompok yang berisiko diantaranya responden dengan kelompok umur $<20$ tahun dan $>35$ tahun. Kelompok umur kurang dari 20 tahun termasuk kelompok yang masih rentan dalam hal kesiapan alat reproduksi dalam menjalani kehamilan serta belum memiliki kematangan dalam hal kondisi psikologis dan sosial.

Kehamilan pada usia >35 tahun akan mempengaruhi tingginya morbiditas kehamilan yang berhubungan dengan kerja jantung dikarenakan penuaan mengarah pada kerusakan non-spesifik dari sebagian besar fungsi fisiologis. Penuaan mengarah pada kerusakan non-spesifik dari sebagian besar fungsi fisiologis disertai dengan beban kehamilan yang dapat menyebabkan penurunan fungsi organ. Kondisi ini yang bisa memicu terjadinya hipertensi kronis, diabetes mellitus, risiko gagal ginjal, morbiditas jantung akut pada wanita hamil berusia 35 tahun atau lebih. Hasil penelitian ini sejalan dengan Lisonkova, 2017 bahwa morbiditas maternal yang berat secara signifikan terjadi pada ibu dengan usia antara 25-29 tahun dan angka kejadian meningkat pada usia lebih dari 39 tahun. Namun berbeda dengan penelitan Huda, 2007 bahwa umur tidak berhubungan secara signifikan dengan komplikasi obstetri.

Sosial ekonomi yang rendah juga berpengaruh secara signifikan terhadap kejadian morbiditas maternal. Penelitian Sirait, 2012 diperoleh hasil tidak ada hubungan yang signifikan antara sosial ekonomi dengan hipertensi pada kehamilan meskipun sebagian besar hipertensi kehamilan terjadi pada ibu dengan sosial ekonomi rendah. Sosial ekonomi yang rendah berdampak pada konsumsi makanan ibu hamil setiap harinya. Ibu hamil lebih mengutamakan suami dan anaknya dalam hal makanan serta menu makanan lebih diutamakan nasi yang mengenyangkan dibandingkan ikan, karena pendapatan keluarga yang kurang mampu untuk memenuhi untuk konsumsi ikan. Selain itu juga rendahnya pendapatan keluarga menuntut ibu hamil untuk melakukan pekerjaan tambahan yang menghasilkan upah seperti menjadi buruh tani, menjahit sepatu dan lain-lain selain mengerjakan pekerjaan rumah tangga. Konsumsi makanan berprioritas pada karbohidrat dan beban kerja tambahan yang menjadikan kondisi fisik tubuh selama kehamilan menurun dan menyebabkan komplikasi selama kehamilan.

Beban kerja ibu yang semakin berat pada waktu menghadapi kehamilan karena harus menjalankan peran reproduktif dan produktif mempengaruhi derajat kualitas gender pada wanita yang berdampak pada juga kualitas kesehatan ibu selama kehamilan dan sampai dengan 42 hari setelah melahirkan. Kesetaraan gender dalam hal melaksanakan peran penting sekali untuk meningkatkan kualitas kesehatan ibu ketika menghadapi kehamilan. Kesetaraan gender yang dimaksud adalah kedudukan yang sama antara suami dan istri dalam melaksanakan peran Repoduktif, produktif dan sosial, meskipun hamil dan melahirkan merupakan tugas istri diharapkan suami dapat ikut berperan serta kesehatan reproduksi ibu yang berdampak positif menurunkan kejadian morbiditas maternal. Pada penelitian ini ditemukan bahwa kualitas gender yang kurang baik 9,788 kali berisiko menyebabkan morbiditas maternal dibandingkan kualitas gender yang baik.

Kualitas gender yang kurang baik dikarenakan peran yang dilaksanakan ibu selama kehamilan tidak hanya peran reproduktif saja tetapi harus ditambah dengan peran produktif dan sosial meskipun dalam kehamilannya. Peran reproduktif dalam hal mengerjakan pekerjaan rumah tangga dan mengasuh anak harus di tanggung sendiri dan jarang sekali suami membantu dalam mengerjakan pekerjaan tersebut. Suami beranggapan karena itu adalah tugas utama seorang istri sedangkan tugas suami hanya mencari nafkah. Ibu juga beranggapan pekerjaan yang menghasilkan upah itu seperti menjahit sepatu dirumah, berdagang, menjadi guru mengaji, pergi ke sawah bukanlah suatu symbol yang menunjukkan bahwa statusnya seorang ibu bekerja karena pekerjaan bukan pekerjaan non formal. Hal ini ditunjukan ketika dilakukan wawancara jawabannya adalah ibu 
rumah tangga akan tetapi setelah dilakukan wawancara mendalam ternyata ibu memiliki aktifitas yang dapat menambah pendapatan keluarga.

Peran suami dalam melakukan pekerjaan rumah tangga penting untuk menjaga kesehatan ibu dan bayi ketika hamil. Pada masyarakat mimika, mencari bahan makanan dan memasak adalah tugas utama istri sedangkan suami bertugas berburu, perang dan membuat rumah. Tugas ini semakin berat ketika harus berpindah ke pemukiman baru Karena tempat untuk mencari dan memasak makanan semakin jauh, namun suami yang membantu meringankan pekerjaan istri ini hanya sedikit. Keadaan ini memberatkan kesehatan wanita pada masa kehamilan di sertai pula adanya budaya bahwa ketika umur kehamilan lebih dari 5 bulan harus banyak digunakan bekerja untuk memperlancar persalinan. Karena percaya mitos ini adalah suatu fakta yang harus diyakini sehingga ibu hamil di mimika melakukan pekerjaan tersebut dengan senyuman (Alwi, 2007).

Peran suami penting dalam meningkatkan kualitas kesehatan ibu selama kehamilan sampai dengan masa nifas. Selama ini sedikit sekali keterlibatan suami dalam hal berKB, pendampingan persalinan karena adanya pemikiran kehamilan dan persalinan adalah suatu hal yang wajar dan kodrat seorang ibu. Padahal suami memegang peran utama dalam kesehatan ibu dan bayi. Keterlibatan suami selama kehamilan bisa ditunjukkan dengan memperhatikan makanan yang dikonsumsi ibu hamil, selalu mendampingi untuk melakukan pemeriksaan kehamilan, menjaga kondisi psikologis ibu, memberi dukungan untuk melakukan persalinan di tenaga kesehatan, ikut membantu melakukan pekerjaan rumah tangga sehingga terpenuhi kebutuhan istirahat ibu hamil (Ishak, 2005).

Kemitrasejajaran antara suami dan istri dalam melaksanakan peran merupakan upaya pembangunan nasional dalam mewujudkan keadilan gender. Suami dan istri memiliki hak dan tanggung jawab yang sama misal mencari nafkah untuk keluarga bukan lagi tugas utama suami namun menjdai tanggung jawab antara suami dan istri begitu pula pekerjaan rumah tangga tidak hanya tugas istri tetapi menjadi tanggung jawab berdua. Perbedaan peran antara suami dan istri dimana suami sebagai pencari nafkah dan istri bertugas mengurus rumah tangga dibentuk oleh norma sosial sehingga penting sekali pemahaman tentang peran wanita dalam pembangunan berwawasan gender di kalangan masyarakat. Gender dalam bahasa inggris mengandung arti jenis kelamin yang dilihat bukan dari secara fisik akan tetapi dari aspek norma/nilai sosial. Peran gender yaitu peran yang dibentuk oleh norma sosial bisa berubah dari waktu ke waktu karena pengaruh perkembangan teknologi ataupun pendidikan dan sebagainya, tidak dilihat dari jenis kelamin. Peran gender di bagi menjadi tiga terdiri dari produktif, reproduktif/domestic, sosial/kemasyarakatan. Peran produktif adalah peran yang dikerjakan dapat menghasilkan barang atau jasa serta dapat menambah penghasilan keluarga. Peran domestic yaitu peran yang berhubungan dengan mengurus rumah tangga. Peran kemasyarakatan adalah pekerjaan yang dilakukan berkaitan dengan kegiatan diamsyarakat atau organisasi (Sudarta, 2007).

Beban kerja adalah salah satu bentuk ketidakadilan gender selain stereotipe, marjinalisasi, subordinasi, diskriminasi, dan tindak kekerasan. Wanita sejak zaman purba sudah menjalan peran domestic dengan mengolah hasil buruan untuk di tukarkan barang lain yang bisa memenuhi kebutuhan pangan keluarga. Pada era agraris dan industry wanita/ibu terlibat dalam peran memenuhi kebutuhan keluarga dengan bekerja di sawah, berjualan. Dengan adanya perkembangan zaman yang semakin maju, tuntutan ibu untuk bekerja produktif diluar rumah semakin tinggi, sehingga perlu keseimbangan dan kerjasama antara suami dan istri dalam menjalankan peran repoduktif. Konflik yang muncul akibat terabaikan dalam melakukan fungsi peran reproduktif suami dan istri adalah tingginya angka perceraian, kekerasan, kenakalan remaja, seks bebas, perkosaan, stress (Sopari, 2013).

$$
\text { Suami juga berperan dalam }
$$
memberikan dukungan kepada istri untuk datang memeriksakan kehamilan ke petugas kesehatan selain harus memberikan informasi positif tentang kesehatan kehamilan. Hasil uji analisis penelitian diperoleh hasil yang 
signifikan antara jumlah kunjungan ibu hamil dengan morbiditas maternal. Ibu terkadang berfikir kehamilan adalah kondisi normal dan wajar dihadapi seorang wanita sehingga tidak memerlukan perhatian khusus dari suami sehingga suami tidak terlibat dalam pengambilan keputusan dalam hal tempat pemeriksaan kehamilan. Ibu dengan berpendidikan rendah dan pengetahunan kurang berdampak negatif tentang tempat periksa kehamilan karena lebih memilih dukun sebagai tempat pemeriksaan dibandingkan petugas kesehatan (Alwi, 2007). Hasil penelitian Ishak, 2005 suami berkontribusi besar dalam pemeriksaan antenatal care ibu hamil yang dimulai sejak terlambat datang haid dalam pemilihan tempat pemeriksaan, persiapan transportasi dan biaya untuk periksa.

\section{KESIMPULAN}

Faktor risiko yang berpengaruh terhadap morbiditas maternal meliputi faktor umur, sosial ekonomi, jumlah kunjungan antenatal care dan kualitas gender. Kualitas gender memiliki nilai OR paling besar dibandingkan variabel lainnya yaitu Morbiditas maternal 17,864 kali disebabkan oleh kualitas gender kurang baik dibandingkan kualitas gender baik.

\section{DAFTAR PUSTAKA}

Callaghan, William M, MD, MPH. 2018. Maternal Mortality and Severe Maternal Morbidity. Clinical obstetrics and gynecology, Volume 61, p 294-295, diakses dari https://www.ncbi.nlm.nih.gov/pmc/articl es/PMC6530783/

Tabassum Firoz, Doris Chou,Peter von Dadelszen, Priya Agrawal, Rachel Vanderkruik, Laura A Magee, Nynke van Den Broek, Lale Say, Ozge Tunçalp. 2013. Measuring Maternal Health: Focus On Maternal Morbidity. Bulletin of the World Health Organization. Diakses dari https://www.scielosp.org/scielo.php?pid $=\mathrm{S} 0042-$

96862013001000794\&script=sci_arttext $\& \operatorname{tlng}=\mathrm{es}$

WHO. 2019. Maternal Health In Nigeria: Generating Information For Action. Di akses dari https://www.who.int/reproductivehealth/ maternal-health-nigeria/en/

Aeni, Nurul. 2013. Faktor Risiko Kematian Ibu. Kesmas: National Health Public Journal

L Ghulmiyyah, MD, Baha Sibai, MD. 2012. Maternal Mortality From Preeclampsia/Eclampsia. Seminar In Perinatology, Volume 36, p 56-59. Di akses dari https://www.sciencedirect.com/science/a rticle/abs/pii/S0146000511001571

NM. Ibraheem, Dr. 2016. Assessment of the epidemiological characteristics of preeclampsia among delivered women attending Tikrit Teaching Hospital. Medical Journal of Tikrit diakses dari https://www.iasj.net/iasj?func=fulltext\& aId $=122051 \backslash$

Budi Rajab. 2009. Kematian Ibu: Suatu Tinjauan Sosial-Budaya. Jurnal Masyarakat \& Budaya, Volume 11, No. 2

Sarka Lisonkova, Jayson Potts, Giulia M. Muraca, Neda Razaz, Yasser Sabr, Wee Shian Chan, Michael S. Kramer. 2017. Maternal Age And Severe Maternal Morbidity: A Population-Based Retrospective Cohort Study. Di akses dari

https://journals.plos.org/plosmedicine/art icle?id=10.1371/journal.pmed. 1002307

Huda, Lasmita Nurul. 2007. Hubungan Status Reproduksi, Status Kesehatan, Akses Pelayanan Kesehatan Dengan Komplikasi Obstetri Di Banda Sakti, Lhokseumawe Tahun 2005. Jurnal Kesehatan Masyarakat Nasional, Volume 1, Nomor 6

Sirait, Anna Maria. 2012. Prevalensi Hipertensi Pada Kehamilan Di Indonesia Dan Berbagai Faktor Yang Berhubungan (Riset Kesehatan Dasar 2007). Buletin Penelitian Sistem Kesehatan, Volume 15, Nomor 2, p 103-109

Alwi, Qomariah. 2007. Tema Budaya Yang Melatarbelakangi Perilaku Ibu-Ibu Penduduk Asli Dalam Pemeliharaan Kehamilan Dan Persalinan Di 
Kabupaten Mimika. Buletin Peneltian Kesehatan, Volume 35, p137-147

S Ishak, Lestari Kanti Wiludjeng, Tjut maimunah TM. 2005. Keterlibatan Suami Dalam Menjaga Kehamilan Istrl Di Puskesmas Kecamatan Kuta Alam Banda Aceh Provinsi Nangroe Aceh Darrusalam. Buletin Penelitian Sistem Kesehatan, Volume 8, p 100-106

Sudarta, Wayan. 2007. Peranan Wanita Dalam Pembangunan Berwawasan Gender. Jurnal Studi Jender Srikandi, Volume 3, Nomor 1

Sopari, Asep. 2013. Gender Dan Kependudukan Serta Implikasinya Dalam Pembangunan Di Indonesia. Di akses dari https://s3.amazonaws.com/academia.edu.d ocuments/32277808/data_sikap_perilaku. pdf?response-content-

disposition=inline $\% 3 \mathrm{~B} \% 20$ filename $\% 3 \mathrm{D}$

GENDERDANKEPENDUDUKAN_SER

TAIMPLIKASINYAD.pdf \&X-Amz-

Algorithm=AWS4-HMAC-SHA256\&X-

Amz-

Credential=AKIAIWOWYYGZ2Y53UL3

A\%2F20190726\%2Fus-east-

1\%2Fs3\%2Faws4_request\&X-Amz-

Date $=20190726 \mathrm{~T} 145942 Z \& X-A m z-$

Expires $=3600 \& X-A m z-$

SignedHeaders $=$ host $\& X-A m z-$

Signature $=1 \mathrm{fdcc} 7 \mathrm{f} 879 \mathrm{fa} 261 \mathrm{bef} 485 \mathrm{fb} 45 \mathrm{~b} 0$

a01ac8650d8d27a4f4523ceabbab8a2ee30a

e 